\title{
Khat use and perceived health problems among African migrants in Australia: an exploratory study
}

Craig Cumming ${ }^{1,3}$ Julia Butt, ${ }^{1}$ Abdi Hersi, ${ }^{4}$ Ahmed Tohow ${ }^{5}$ and Jesse Young ${ }^{1,2,3}$

${ }^{1}$ National Drug Research Institute, Curtin University, Perth, Western Australia, Australia (Correspondence to: Craig Cumming: craig.cumming@uwa.edu. au). ${ }^{2}$ Melbourne School of Population and Global Health, University of Melbourne, Parkville, Victoria, Australia. ${ }^{3}$ Centre for Health Services Research, School of Population Health, The University of Western Australia, Perth, Western Australia, Australia. ${ }^{4}$ Griffith Centre for Social and Cultural Research, Griffith University, Brisbane, Queensland, Australia. ${ }^{5}$ Global Somali Diaspora Advisory Team, Melbourne, Victoria, Australia.

\begin{abstract}
Background: The chronic use of khat, a plant with psychostimulant properties, has been associated with physical and mental health problems. Previous research found that non-khat users were more likely than khat users to perceive its use to be associated with poor health.
\end{abstract}

Aims: We aimed to identify differences in the perception of specific khat-associated health problems between khat users and non-users.

Methods: In 2012, 133 adults ( $\geq 18$ years) from African migrant communities in 4 state capital cities in Australia completed questionnaires to ascertain their perception of whether specific health problems were associated with khat use. Multivariable log-linked Poisson regression was used to compare the perceptions of the 2 groups and identify differences, adjusting for sociodemographic factors, tobacco use and years living in Australia.

Results: Overall, 58 (44\%) and 75 (56\%) participants reported current khat use and no use respectively. Adjusted log-linked Poisson regression showed that people who use khat were less likely than non-users to perceive certain health and related problems were associated with khat use, including, poor health in general [prevalence risk ratio (PRR) $=0.86 ; 95 \% \mathrm{CI}$ : 0.75 , 1.00]; laziness $(\mathrm{PRR}=0.86$; 95\% CI: 0.75, 0.99); stomach and throat problems (PRR = 0.83; 95\% CI: 0.72, 0.96); and teeth, gum and mouth problems (PRR $=0.81 ; 95 \% \mathrm{CI}: 0.67,0.99)$.

Conclusions: Khat users are less likely to perceive use being associated with health problems than non-users. Providing information on the health problems associated with khat use may be an important component of health promotion strategies and interventions aimed at minimising khat-related harm.

Keywords: khat use/non-use, health perceptions, African migrant communities, Australia

Citation: Cumming C; Butt J; Hersi A; Tohow A; Young J. Khat use and perceived health problems among African migrants in Australia: an exploratory study. East Mediterr Health J. 2021;27(5):491-500. https://doi.org/10.26719/2021.27.5.491

Received: 18/09/19; accepted: 31/05/20

Copyright (c) World Health Organization (WHO) 2021. Open Access. Some rights reserved. This work is available under the CC BY-NC-SA 3.0 IGO license (https://creativecommons.org/licenses/by-nc-sa/3.o/igo)

\section{Introduction}

Khat (Catha edulis), is a plant with psychostimulant properties $(1,2)$, the leaves have been traditionally chewed by people in the horn of Africa and the Arabian Peninsula. Recent migration has led to its use in other countries $(3,4)$, including Australia (5). Data regarding khat use is not routinely collected in Australia and there is little robust evidence about the rates of use internationally, with estimates suggesting that around 20 million people use khat globally $(6,7)$. Despite a lack of prevalence data in the Australian community, there are clear concerns among members of the East-African diaspora in Australia about the health and social impacts associated with khat use (8).

There is increasing evidence of a range of physical and mental health conditions associated with chronic khat use (9). These include heart disease (10-12), digestive system problems (13), hepatic disease (14), depression (15), post-traumatic stress disorder (16) and psychosis $(16,17)$. Chronic khat use has been positively associated with both initiating and increased tobacco use (18), using alcohol and other drugs (4) and other poor outcomes such as a decrease in quality of life and academic functioning (19). Recent findings also suggest a high dependence liability for khat $(5,20)$, with withdrawal symptoms reported in the period after cessation (21). Additionally, people who use khat can develop a khat-use disorder that meets DSM-V criteria (22) for substance use disorder (19). Thus chronic khat use is a potential public health concern that warrants further investigation in order to identify options for intervention.

The traditional context of khat use has been in cultural and religious ceremonies (23) and in facilitating community dispute resolution (24). Furthermore, it is perceived as socially acceptable in migrant groups with northern African and Yemeni heritage living in the United Kingdom (25) and among the Somali community in Australia (26). Despite this, prior research has identified that people who use khat and those close to them have perceived physical and mental health problems associated with using khat, including gastrointestinal problems, sleeping problems, hallucination and anxiety 
$(8,27)$. Additionally, members of khat-using communities have perceived that khat use is related to negative social and family consequences, including neglect of social responsibilities, family breakdown and family violence $(8,28)$.

To date, 2 studies have looked at the differences in perception of health problems associated with khat use between people who use khat and those who do not $(27,29)$. An Ethiopian study has included a limited analysis of the differences in the perceived health problems associated with khat use between people who use khat and those who do not (27). Bivariate analysis found that participants who did not perceive a negative impact on health from khat use were 5 times more likely to use khat compared to those who perceived a negative impact on health (27); however, the study did not disaggregate by which specific health problems were perceived as being associated with khat use. Raising awareness and modifying the perception of specific khat-related health problems in people who use khat may be a crucial step towards intervention and prevention of harm.

In Yemen, Wedegaertner et al. investigated the differences in perception between people who did and did not use khat with respect to whether they perceived that it was associated with a range of social, psychosocial, physical and mental health-related outcomes (29). Their main findings were that males identified more strongly with khat use than females, females cited the negative impact on health and self-esteem among the family as major concerns, and male abstainers were more likely than males who used khat to believe that khat use causes social problems.

Previous research has demonstrated an inverse relationship between risk or harm perception associated with using a particular substance and the actual use of that substance, particularly for smoking tobacco through a hookah $(30,31)$ and using cannabis (32). An increased perception of risk has also been found to increase the intention to quit smoking tobacco (33). Thus, increased understanding of the difference in perception between those who use khat and those who do not may provide an initial framework for the development of interventions aimed at reducing khat-related harm.

To build on the understanding between drug use and perception of drug use in relation to khat, we conducted a study in a developed-country setting that investigated the differences in the perception of khat use being associated with health problems between people who do and people who do not use khat who were members of a diaspora where khat use is prevalent. We hypothesised that overall people who use khat will be less likely to perceive a positive association between khat use and health problems than people who do not use khat. Accordingly, we aimed to: describe the perceptions of physical and mental health and social problems for people who use khat and abstainer members of migrant communities in Australia; estimate the association between current khat use and perceived physical and mental health and social problems; and identify potential targets to inform on harm minimization and educational interventions for people who use khat and those living in communities where khat use occurs.

\section{Methods}

\section{Study design and participants}

This study is part of a broader study which utilised Rapid Assessment Methodology (RAM) to examine khat use in Australia. The study consulted with key informants and health providers and used focus groups as well as the questionnaire methodology on which the current data is based. Rapid Assessment Methodology has been used to investigate psychostimulants previously in diverse social and cultural settings, having been asserted as effective $(34,35)$.

The study design and participant recruitment have been detailed elsewhere (5). Briefly, participants were recruited through African community health liaison officers and snowball sampling. The participants were 133 adults ( $\geq 18$ years) from African migrant communities in 4 state capital cities in Australia (Brisbane, Melbourne, Adelaide and Perth) recruited for the study between 1 April and 1 June 2012. There were 58 (43.6\%) participants who reported current khat use, whilst the remaining 75 (56.4\%) reported not using khat currently.

The Curtin University Human Research Ethics Committee approved the study, and community consultation showed support for the study methods.

\section{Measures}

Based on a review of the literature, 2 questionnaires were developed in English to identify potential health problems associated with khat use. One was developed for people currently using khat, with the other for abstainers. Regardless of their self-reported khat user status, each participant answered identical questions to assess their characteristics across a number of domains, including sociodemographic, alcohol and other drug use, and their perception of the impact of khat use on a range of physical and mental health conditions. Participants were asked to use a 5-point Likert scale to endorse whether they believed using khat was associated with specific health conditions that have been associated with khat use in the literature. Their responses were collapsed dichotomously with agree/strongly agree responses coded as an endorsement and all other responses (strongly disagree/disagree/neutral) coded as not endorsing the proposed effect of khat use on each specified health outcome. People who reported not currently using khat were also asked if they had used in the past. The questionnaires were translated into Amharic, Arabic, Somali and Swahili, the languages of the main geographic regions where khat is used. The relevant questionnaire was administered to participants based upon their current khat user status.

\section{Statistical methods}

Descriptive statistics were calculated for all measures. Fisher's exact test was used to compare differences be- 
tween the khat user and abstainer groups for dichotomous and categorical outcomes. An independent samples t-test was used to compare time spent in Australia between these groups. Age was included in the questionnaire as a 4-category variable. In univariate analyses, age was analysed as a 4-category variable as well as a dichotomous variable ( $\leq 35$ and $>35$ years determined by reference to evidence suggesting that drug use behaviour changes by this age (36) and the practical constraints of the categories used to collect the data) to determine which was the most parsimonious format to be used for regression analyses.

Modified log-linked Poisson regression with robust error variance was used to model the association between khat use status and attitudes towards the health impact of khat use, as previously recommended (37). This valid alternative to logistic regression for modelling binary outcomes in cross-sectional studies (38) estimates relative risk instead of an odds ratio and, unlike logistic regression, is not subject to bias when the outcome is rare or exceedingly common (39). The adjusted model controlled for sex, age (as a 4-category variable), employment status, daily tobacco use and total years in Australia.

To test if close contact (i.e. in social or family settings) with people who use khat affects the perception of khat-related harms, we conducted subgroup analyses restricted to the abstainer group comparing the responses of abstainers who were living with a person who used khat at the time with those who were not. Additionally, we hypothesised that abstainers who had used khat previously may have different perceptions about the health problems of khat use compared to abstainers who had never used khat. Accordingly, we conducted subgroup analyses restricted to the abstainer group comparing the responses of those who reported previous khat use versus those who reported they had never used khat. All analyses were conducted using STATA, version 14.0.

\section{Results}

Group demographics are reported in Table 1. The khat user and abstainer groups differed statistically significantly in age $(P=0.042)$. Participants in the user group were statistically significantly more likely to report smoking tobacco daily $(P<0.001)$ and to have spent significantly fewer years in Australia $(P=0.037)$.

Fisher's exact test analyses of the proportion of participants who endorsed health outcomes associated with khat use in each group is displayed in Table 2. Abstainers were statistically significantly more likely than users to endorse that "khat use makes people lazy after use" $(P=0.003)$; "is bad for blood pressure" $(P=$ 0.022); "is bad for the stomach and throat" $(P=0.002)$; and "makes people more unhealthy" $(P=0.050)$. There was no difference between the groups for endorsement that khat use does not affect health, with a reasonably large proportion of participants endorsing this in both groups (35.3\% and $42.9 \%$ in the user and abstainer groups respectively).

The association between current khat use and the perceived harms due to khat use is reported in Table 3. After adjustment for model covariates, current khat users were less likely to perceive that "khat use makes people lazy after use" [prevalence risk ratio $(P R R)=0.86 ; 95 \% \mathrm{CI}$ : 0.75-0.99]; "it is bad for the stomach and throat" (PRR = 0.83; 95\% CI: 0.72-0.96); "it makes people more unhealthy" (PRR $=0.86 ; 95 \% \mathrm{CI}: 0.75-1.00)$, whilst "it is bad for the teeth, gums, and mouth" (PRR = 0.81; 95\% CI: 0.67-0.99). Significant unadjusted associations were observed between the khat user group and perceptions that khat use "makes people not eat properly" (PRR $=0.86$; 95\% CI: 0.75-1.00); "makes people anxious" (PRR $=0.86 ; 95 \% \mathrm{CI}$ : $0.75-0.98)$; "is bad for the heart" (PRR = 0.85; 95\% CI: 0.730.99); and "makes people hear voices or see things that are not real" (PRR $=0.87$; 95\% CI: 0.75-1.00), however these associations were attenuated to the null after adjustment for model covariates.

Subgroup analysis of abstainers who did and did not currently live with a person who used khat found no differences in association of khat use between the subgroups for all outcomes except for those who did not currently live with a person who uses khat being more likely to perceive that it makes people depressed $(P=$ o.017) (Table 4). No differences were observed between abstainers who reported using khat previously and people who reported never using khat.

\section{Discussion}

Evidence to inform the development of prevention strategies and culturally-appropriate interventions for migrant groups has been highlighted as a key component of inclusion health (40). A nuanced understanding of how people who use khat perceive health problems associated with its use is an important step in identifying specific targets for health promotion and education. Highlighting the specific khat-related health problems that we found are perceived differently by those using and abstaining from khat is likely to be an important component of any educational intervention.

Our findings suggest that our hypothesis was correct: people abstaining from khat are more likely than those using it to perceive that khat use resulted in poorer overall health. One contradiction in our data is that a relatively large proportion of participants in each group endorsed that khat use was not associated with health problems. It is likely that this questionnaire item was not well understood. Specifically however, abstainers were more likely than users to perceive that khat use has a negative impact on health generally, results in poorer oral health, contributes to stomach and throat problems, and makes people lazy. These findings are similar to those of Wedegaertner et al., who found people using khat had less concerns than abstainers about the negative effects of its use (29). Our findings also have similarities with prior research into cannabis and tobacco use that found 
Table 1 Demographic characteristics of study participants (adults from African migrant communities living in Australia) at the time of questionnaire completion

\begin{tabular}{|c|c|c|c|c|c|c|c|}
\hline \multirow[t]{2}{*}{ Characteristic } & \multicolumn{2}{|c|}{$\begin{array}{l}\text { Khat users } \\
\quad(n=58)\end{array}$} & \multicolumn{2}{|c|}{$\begin{array}{l}\text { Non users } \\
(n=133)\end{array}$} & \multicolumn{2}{|c|}{$\begin{array}{c}\text { Total } \\
(n=133)\end{array}$} & \multirow[t]{2}{*}{ P-value $^{a}$} \\
\hline & No. & $\%$ & No. & $\%$ & No. & $\%$ & \\
\hline Age (years) & & & & & & & 0.042 \\
\hline $18-25$ & 21 & 36.2 & 14 & 19.2 & 35 & 26.7 & \\
\hline $26-35$ & 15 & 25.9 & 24 & 32.9 & 39 & 29.8 & \\
\hline $36-45$ & 10 & 17.2 & 22 & 30.1 & 32 & 24.4 & \\
\hline$>45$ & 12 & 20.7 & 13 & 17.8 & 25 & 19.1 & \\
\hline Total & & & & & 131 & 98.5 & \\
\hline Age (years) & & & & & & & 0.289 \\
\hline$\leq 35$ & 36 & 62.1 & 38 & 52.1 & 74 & 56.5 & \\
\hline$>35$ & 22 & 37.9 & 35 & 47.8 & 57 & 43.5 & \\
\hline Total & & & & & 131 & 98.5 & \\
\hline Sex & & & & & & & 0.503 \\
\hline Male & 49 & 84.5 & 59 & 78.7 & 108 & 81.2 & \\
\hline Female & 9 & 15.5 & 16 & 21.3 & 25 & 18.8 & \\
\hline Total & & & & & 133 & 100.0 & \\
\hline Employment status & & & & & & & 0.703 \\
\hline Full-time & 24 & 41.4 & 34 & 46.6 & 58 & $44 \cdot 3$ & \\
\hline Part-time/ casual/ contract & 16 & 27.6 & 18 & 24.7 & 34 & 25.9 & \\
\hline Student/home duties/ volunteer & 9 & 15.5 & 14 & 19.2 & 23 & 17.6 & \\
\hline Unemployed/pension & 9 & 15.5 & 7 & 9.6 & 16 & 12.2 & \\
\hline Total & & & & & 131 & 98.5 & \\
\hline Consumes alcohol & & & & & & & 0.582 \\
\hline Yes & 7 & 12.7 & 7 & 9.6 & 14 & 11 & \\
\hline No & 48 & 87.3 & 66 & 90.4 & 114 & 89 & \\
\hline Total & & & & & 128 & 96.2 & \\
\hline Smokes tobacco daily & & & & & & & $<0.001$ \\
\hline -yes & 32 & 55.2 & 6 & 8.0 & 38 & 28.6 & \\
\hline- no & 26 & 44.8 & 69 & 92 & 95 & 71.4 & \\
\hline Total & & & & & 133 & 100 & \\
\hline \multirow[t]{3}{*}{ Years spent in Australia } & 51 & 87.9 & 65 & 86.7 & 116 & 87.2 & $0.037^{b}$ \\
\hline & Mean & SD & Mean & SD & Mean & SD & \\
\hline & 7.37 & 5.64 & 9.78 & 6.44 & 8.72 & 6.19 & \\
\hline
\end{tabular}

${ }^{a}$ Fisher's exact test.

'Independent samples t-test.

an inverse relationship between using a substance and the perceived risk associated with its use $(30,32,33)$.

Our research expands on previous studies by Omar et al. (8), Zeleke et al. (27) and Wedegaertner et al. (29) which identified health problems perceived to be associated with khat use in communities where khat use is prevalent. Zeleke et al. reported that $92 \%$ of participants endorsed at least one khat-related health problem (27), but they did not compare perceptions of those using and those abstaining. Wedegaertner et al. did report differences in perceived harms associated with khat use between these groups (29), however they primarily focused on gender differences.
Our finding that people using khat were less likely than abstainers to perceive khat use being associated with oral health and stomach and throat problems is important in light of the evidence that khat chewing is associated with poor oral health $(41,42)$ and digestive health problems $(13,43)$. These health problems are obvious inclusions for any educational and health promotion efforts around khat use and its associated harms.

Our finding that abstainers are more likely than those using khat to perceive an association between khat use and laziness is interesting, with recent research into khat withdrawal identifying tiredness and poor motivation along with depression and irritability among the symptoms that were experienced at their 
Table 2 Endorsement (agree/strongly agree) of health outcomes associated with khat use among adults from African migrant communities living in Australia: primary question "Do you think that khat affects peoples' health?"

\begin{tabular}{|c|c|c|c|c|c|c|c|}
\hline \multirow[t]{2}{*}{ Response } & \multicolumn{2}{|c|}{$\begin{array}{l}\text { Khat user } \\
(n=58)\end{array}$} & \multicolumn{2}{|c|}{$\begin{array}{l}\text { Non-user } \\
(n=75)\end{array}$} & \multicolumn{2}{|c|}{$\begin{array}{c}\text { Total } \\
(n=133)\end{array}$} & \multirow[t]{2}{*}{ P-value } \\
\hline & No. & $\%$ & No. & $\%$ & No. & $\%$ & \\
\hline No, it does not affect health & 18 & $35 \cdot 3$ & 30 & 42.9 & 48 & 39.7 & 0.454 \\
\hline Total & & & & & 121 & 91 & \\
\hline It makes people not eat properly & 38 & 73.1 & 56 & 78.9 & 94 & 76.4 & 0.521 \\
\hline Total & & & & & 123 & 92.5 & \\
\hline It makes people lazy after using & 27 & 51.9 & 55 & 78.6 & 82 & 67.2 & 0.003 \\
\hline Total & & & & & 122 & 91.8 & \\
\hline It makes people smoke more & 38 & 74.5 & 48 & 69.6 & 86 & 71.7 & 0.682 \\
\hline Total & & & & & 120 & 90.2 & \\
\hline It makes people anxious & 32 & 60.4 & 52 & 75.4 & 84 & 68.9 & 0.114 \\
\hline Total & & & & & 122 & 91.8 & \\
\hline It is bad for blood pressure & 25 & 49.0 & 48 & 70.6 & 73 & 61.3 & 0.022 \\
\hline Total & & & & & 119 & 89.5 & \\
\hline It is bad for the stomach and throat & 29 & 55.8 & 60 & 82.2 & 89 & 71.2 & 0.002 \\
\hline Total & & & & & 125 & 94.0 & \\
\hline It is bad for the kidneys & 31 & 58.5 & 46 & 67.6 & 77 & 63.6 & 0.343 \\
\hline Total & & & & & 121 & 91.0 & \\
\hline It is bad for the heart & 27 & 51.9 & 49 & 70.0 & 76 & 62.3 & 0.059 \\
\hline Total & & & & & 122 & 91.8 & \\
\hline People are more unhealthy & 36 & 69.2 & 60 & 84.5 & 96 & 78.0 & 0.050 \\
\hline Total & & & & & 123 & 92.5 & \\
\hline It is not good for teeth/gums/mouth & 45 & 84.9 & 65 & 90.3 & 110 & 88.0 & 0.411 \\
\hline Total & & & & & 125 & 94.0 & \\
\hline $\begin{array}{l}\text { It makes people hear voices or see } \\
\text { things that are not real }\end{array}$ & 28 & 53.8 & 48 & 66.7 & 76 & 61.3 & 0.191 \\
\hline Total & & & & & 124 & 93.2 & \\
\hline It makes people depressed & 31 & 59.6 & 49 & 68.1 & 80 & 64.5 & 0.348 \\
\hline Total & & & & & 124 & 93.2 & \\
\hline Khat is addictive & 39 & 75.0 & 57 & 79.2 & 96 & 77.4 & 0.665 \\
\hline Total & & & & & 124 & 93.2 & \\
\hline
\end{tabular}

Fisher's exact test.

most severe level around 7 days after participants ceased using khat (21). These symptoms may be a factor in problems identified in communities where khat is used, such as family breakdown and unemployment (28) [unemployment being a particular challenge for African immigrants in Australia (44)]. Further research is warranted to develop withdrawal management strategies to assist individuals ceasing khat use, particularly during the first week of cessation.

Further research is needed to develop interventions for addressing khat use in communities where it is prevalent with the dual aims of reducing existing use and preventing uptake. Education to inform community members and leaders about khat-related harms should be a priority. Our findings suggest that it is important to include specific information about established oral (42) and digestive (13) health harms, as well as reduced motivation or sleeping difficulties following ceasing khat use (21). The possibility that khat use can lead to dependence should also be highlighted (9). Additionally, hepatic disease (45) and mental illness (17) should be included in any materials developed. Previous research suggests that, given the cultural context in which khat is used, involving community leaders such as religious leaders in efforts to address and prevent khat use may be warranted (46). Efforts aimed at increasing awareness of khat-related harms should be accompanied by information about available assistance or treatment to cease use.

Our study had several strengths. The participants were members of migrant communities that have previously reported khat-related harm in Australia (28). Given that one of our primary aims was to inform interventions that target this group, their data are highly relevant. Although we generated a convenience sample, extensive community consultation and the use 
Table 3 Modified log-linked Poisson regression of perceived harms for khat users and non-users among adults from African migrant communities living in Australia

\begin{tabular}{|c|c|c|c|c|}
\hline \multirow[t]{2}{*}{ Response } & \multicolumn{2}{|c|}{ Unadjusted } & \multicolumn{2}{|c|}{ Adjusted ${ }^{a}$} \\
\hline & PRR (95\% CI) & P-value & $\operatorname{PRR}(95 \%$ CI $)$ & P-value \\
\hline No, it does not affect health & $0.98(0.87-1.10)$ & 0.724 & $1.04(0.94-1.16)$ & 0.449 \\
\hline It makes people not eat properly & $0.86\left(0.75^{-1.00)}\right.$ & 0.043 & $0.91(0.80-1.05)$ & 0.205 \\
\hline It makes people lazy after using & $0.81(0.72-0.92)$ & 0.001 & $0.86(0.75-0.99)$ & 0.038 \\
\hline It makes people smoke more & $1.01(0.84-1.21)$ & 0.945 & $1.03(0.88-1.19)$ & 0.739 \\
\hline It makes people anxious & $0.86(0.75-0.98)$ & 0.024 & $0.92(0.80-1.05)$ & 0.214 \\
\hline It is bad for blood pressure & $1.00(0.93-1.08)$ & 0.986 & $1.02(0.99-1.04)$ & 0.130 \\
\hline It is bad for the stomach and throat & $0.78(0.69-0.87)$ & $<0.001$ & $0.83(0.72-0.96)$ & 0.012 \\
\hline It is bad for the kidneys & $0.91(0.77-1.08)$ & 0.284 & $0.98(0.84-1.14)$ & 0.799 \\
\hline It is bad for the heart & $0.85(0.73-0.99)$ & 0.036 & $0.94(0.81-1.10)$ & 0.454 \\
\hline People are more unhealthy & $0.84(0.74-0.95)$ & 0.007 & $0.86\left(0.75^{-1.00)}\right.$ & 0.043 \\
\hline It is not good for teeth/gums/mouth & $0.91(0.77-1.07)$ & 0.277 & $0.81(0.67-0.99)$ & 0.035 \\
\hline It makes people hear voices or see things that are not real & $0.87\left(0.75^{-1.00)}\right.$ & 0.044 & $0.94(0.80-1.11)$ & 0.485 \\
\hline It makes people depressed & $0.87(0.76-1.00)$ & 0.052 & $0.91(0.79-1.06)$ & 0.238 \\
\hline Khat is addictive & $0.98(0.84-1.15)$ & 0.812 & $1.09(0.90-1.32)$ & 0.390 \\
\hline
\end{tabular}

$P R R=$ prevalence risk ratio.

${ }^{a}$ Adjusted for sex, age, employment status, daily tobacco use and total years in Australia.

of focus groups contributed to the recruitment of this sample. Another strength was our use of African health liaison officers who were fluent in multiple African languages during interviews with participants. This, in combination with the fact that the questionnaires were translated into 4 additional languages, minimized the chances of information bias due to misunderstanding or misinterpretation during data collection.

Onelimitation of our study is our sample size, meaning we were underpowered to detect differences between groups in univariate analyses. Accordingly, our findings of differences between groups when endorsing laziness, bad for blood pressure, bad for the stomach and throat, and people being generally less healthy being associated with khat use warrant further investigation with a larger sample. Furthermore, our study design generated a convenience sample that may not be representative of the entire population of people who use khat and abstaining members of their communities. A further limitation is that our study investigated participants' perceptions

Table 4 Endorsement (agree/strongly agree) of health outcomes associated with khat use among the non-user subgroup (adults from African migrant communities living in Australia) according to whether they live with a khat user or not

\begin{tabular}{|c|c|c|c|c|c|c|c|c|c|}
\hline \multirow[t]{3}{*}{ Response } & \multicolumn{4}{|c|}{ Lives with khat user } & \multicolumn{2}{|c|}{ Total, $n=75$} & \multicolumn{2}{|c|}{ Total (subgroup) } & \multirow[t]{3}{*}{ P-value ${ }^{a}$} \\
\hline & \multicolumn{2}{|c|}{ Yes $(n=13)$} & \multicolumn{2}{|c|}{ No $(n=58)$} & \multirow[b]{2}{*}{ No. } & \multirow[b]{2}{*}{$\%$} & \multirow[b]{2}{*}{ No. } & \multirow[b]{2}{*}{$\%$} & \\
\hline & No. & $\%$ & No. & $\%$ & & & & & \\
\hline No, it does not affect health & 5 & 45.4 & 25 & 43.1 & 30 & 43.5 & 69 & 92.0 & 1.000 \\
\hline It makes people not eat properly & 8 & 66.7 & 48 & 82.8 & 56 & 80.0 & 70 & 93.3 & 0.240 \\
\hline It makes people lazy after using & 7 & 58.3 & 48 & 84.2 & 55 & 79.7 & 69 & 92.0 & 0.057 \\
\hline It makes people smoke more & 8 & 66.7 & 40 & 71.4 & 48 & 70.6 & 68 & 90.1 & 0.737 \\
\hline It makes people anxious & 6 & $54 \cdot 5$ & 46 & 80.7 & 52 & 76.5 & 68 & 90.1 & 0.113 \\
\hline It is bad for blood pressure & 9 & 75.0 & 39 & 70.9 & 48 & 71.6 & 67 & 89.3 & 1.000 \\
\hline It is bad for the stomach and throat & 10 & 76.9 & 50 & 84.7 & 60 & 83.3 & 72 & 96.0 & 0.444 \\
\hline It is bad for the kidneys & 8 & 66.7 & 38 & 69.1 & 46 & 68.7 & 67 & 89.3 & 1.000 \\
\hline It is bad for the heart & 9 & 69.2 & 40 & 71.4 & 49 & 71.0 & 69 & 92.0 & 1.000 \\
\hline People are more unhealthy & 10 & 76.9 & 50 & 87.7 & 60 & 85.7 & 70 & $93 \cdot 3$ & 0.380 \\
\hline It is not good for teeth/gums/mouth & 12 & 92.3 & 53 & 91.4 & 65 & 91.6 & 71 & 94.7 & 1.000 \\
\hline $\begin{array}{l}\text { It makes people hear voices or see things that } \\
\text { are not real }\end{array}$ & 6 & 46.1 & 42 & 72.4 & 48 & 67.6 & 71 & 94.7 & 0.100 \\
\hline It makes people depressed & 5 & 38.5 & 44 & 75.9 & 49 & 69.0 & 71 & 94.7 & 0.017 \\
\hline Khat is addictive & 10 & 76.9 & 47 & 81.0 & 57 & 80.3 & 71 & 94.7 & 0.711 \\
\hline
\end{tabular}


about health problems associated with khat; these are subjective, and should not be relied upon as further evidence of khat-related harm. Additionally, our findings may not be generalizable to migrant communities outside of Australia. We relied on self-report of a sensitive behaviour, making social desirability bias a possible factor. Lastly, our design is cross-sectional, so we are unable to make causal inferences.

\section{Conclusion}

There is some perception of khat-related health problems, both by people using khat and those abstaining, in communities where khat use is prevalent in Australia. However, people who use khat are less likely to perceive that khat use is associated with health problems than abstainers, particularly in relation to the digestive system and laziness. Targeted health promotion efforts should be aimed at both reducing use in groups already using and preventing initiation of khat use. Health promotion materials should include information on the oral, digestive, hepatic and mental health problems associated with khat use as well as highlighting the potential for dependence, withdrawal symptoms during cessation, and information on the assistance and treatment available to those wishing to cease using.

\section{Acknowledgment}

The authors acknowledge the nonmonetary contribution made to this research by the Somali Australian Council of Victoria, Inc.; Co-Exist New South Wales: Diversity Health Comorbidity Service; and the Islamic Women's Association of Queensland. The authors also recognise the contribution of Ms Irene Ngune in the initial phases of this research.

Funding: The Khat Use in Australia study was commissioned and funded by the Drug Strategy Branch, Department of Health, Commonwealth of Australia. The National Drug Research Institute at Curtin University is supported by funding from the Australian Government under the Substance Misuse Prevention and Service Improvements Grants Fund. Craig Cumming is supported by an Australian Government Research Training Program Scholarship (PhD). Jesse Young receives salary and research support from a National Health and Medical Research Council Investigator Grant (GNT1178027). The funding sources mentioned here had no additional role in the research design; data collection, analysis or interpretation; the writing of the manuscript; or the decision to submit the article for publication.

Competing interests: None declared.

\section{Consommation de khat et problèmes de santé perçus chez les migrants africains en Australie : une étude exploratoire}

\section{Résumé}

Contexte: L'utilisation chronique du khat, une plante aux propriétés psychostimulantes, a été associée à des problèmes de santé physique et mentale. Des recherches antérieures ont révélé que les non-consommateurs de khat étaient plus susceptibles que les consommateurs de percevoir son utilisation comme étant associée à une mauvaise santé.

Objectifs : Notre objectif était d'identifier les différences de perception des problèmes de santé spécifiques liés au khat entre les consommateurs et les non-consommateurs.

Méthodes : En 2012, 133 adultes ( $\geq 18$ ans) issus de communautés de migrants africains dans quatre capitales d'États d'Australie ont répondu à des questionnaires afin de déterminer s'ils percevaient des problèmes de santé spécifiques associés à la consommation de khat. La régression de Poisson log-linéaire multivariable a été utilisée pour comparer les perceptions des deux groupes et identifier les différences, avec ajustement en fonction de facteurs sociodémographiques, de la consommation de tabac et des années de vie passées en Australie.

Résultats : Au total, 58 (44\%) et $75(56 \%)$ participants ont déclaré consommer et ne pas en consommer de khat, respectivement, au moment de l'étude. La régression de Poisson log-linéaire ajustée a montré que les consommateurs de khat étaient moins susceptibles que les non-consommateurs de percevoir certains problèmes de santé et problèmes connexes associés à cette pratique, y compris une mauvaise santé en général [rapport risque/prévalence = 0,86 ; IC à $95 \%: 0,75,1,00$ ] ; la paresse (rapport risque/prévalence $=0,86$; IC à $95 \%: 0,75,0,99$ ) ; les problèmes d'estomac et de gorge (rapport risque/prévalence $=0,83$; IC à $95 \%: 0,72,0,96$ ) ; et les problèmes de dents, de gencives et de bouche (rapport risque/prévalence= 0,81 ; IC à $95 \%: 0,67,0,99$ ).

Conclusions : Les consommateurs de khat sont moins susceptibles de percevoir l'usage comme étant associé à des problèmes de santé que les non-consommateurs. La fourniture d’informations sur les problèmes de santé associés à la consommation de khat peut être une composante importante des stratégies et interventions de promotion de la santé visant à réduire au minimum les méfaits de cette substance. 


\section{تعاطي القات والمشاكل الصحية المثتصورة بين المهاجرين الأفارقة في أستر اليا: دراسة استكشافية \\ كريج كمينج، جوليا بات، عبدي هرسي، أحمد توهو، جيسي ينج \\ الخلاصة}

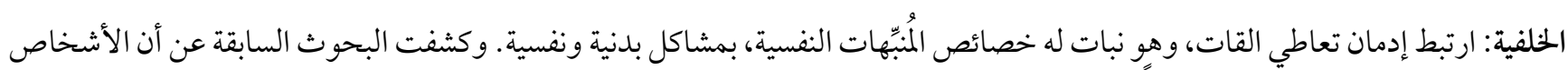

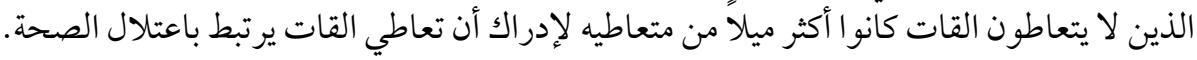

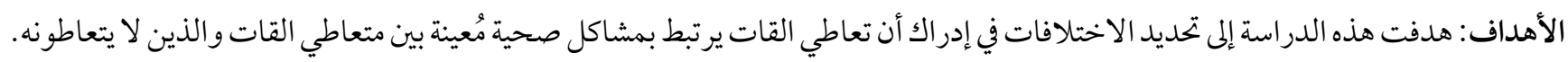

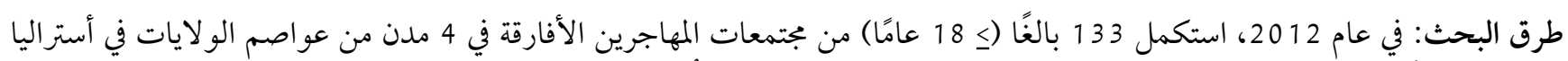

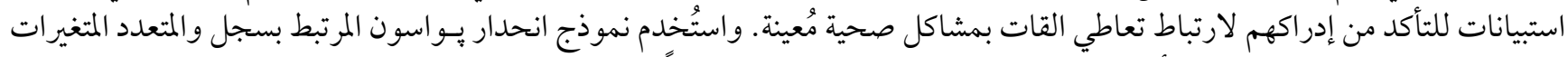

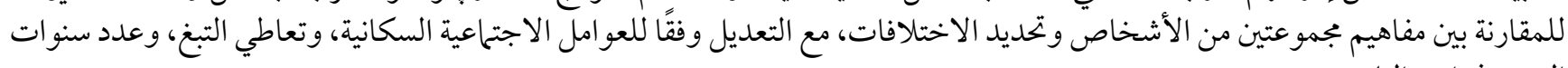
العيش في استراليا.

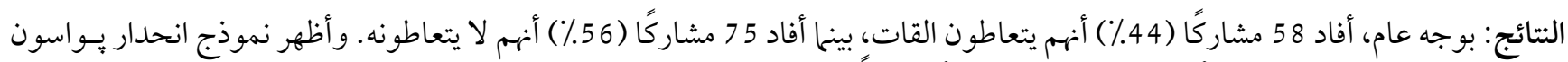

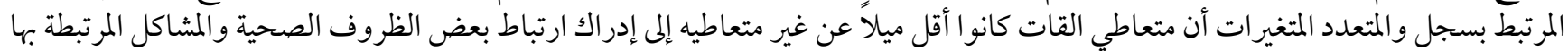

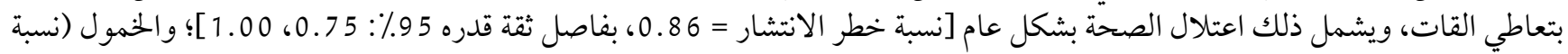

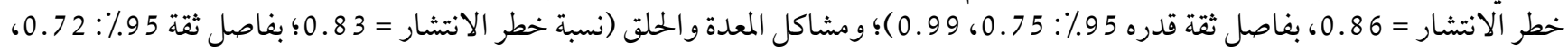

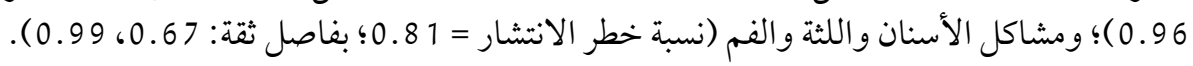

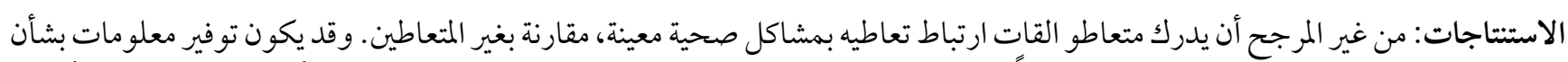

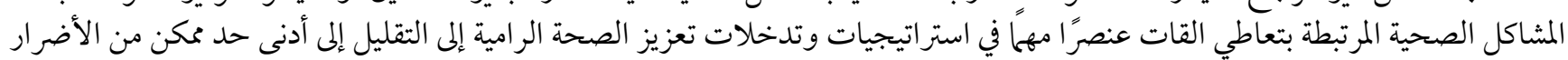
المرتبطة بتعاطيه.

\section{References}

1. Kalix P. Cathinone, an alkaloid from khat leaves with an amphetamine-like releasing effect. Psychopharmacology. 1981;74(3):269-70. doi:10.1007/BF00427108

2. WHO Expert Committee on Addiction-Producing Drugs: thirteenth report. Geneva: World Health Organization; 1964.

3. Swain S, Spracklen K, Lashua BD. Khat-chewing in liminal leisure spaces: British-Somali youth on the margins. Leisure Studies. 2018;37(4):440-51.

4. Nakajima M, Molla K, Belachew B, Mohammed A, Hassan A, Kroll J, et al. Khat use is associated with tobacco, alcohol, and illicit drug use: a cross-sectional examination in the United States. J Psychoactive Drugs. 2017;49(5):413-9. doi:10.1080/02791072.2017.1 342155

5. Young JT, Butt J, Hersi A, Tohow A, Mohamed DH. Khat dependence, use patterns, and health consequences in Australia: an exploratory study. J Stud Alcohol Drugs. 2016 Mar;77(2):343-8. doi:10.15288/jsad.2016.77.343

6. Odenwald M, Klein A, Warfa N. Khat use in Europe: implications for European policy. Drugs in Focus. 2011 January;21.

7. Patel NB. "Natural amphetamine" khat: a cultural tradition or a drug of abuse? Int Rev Neurobiol. 2015;120:235-55. doi:10.1016/ bs.irn.2015.02.006

8. Omar YS, Jenkins A, Altena MvR, Tuck H, Hynan C, Tohow A, et al. Khat use: what is the problem and what can be done? BioMed Res Int. 2015;2015. doi:10.1155/2015/472302

9. Odenwald M, Al'Absi M. Khat use and related addiction, mental health and physical disorders: the need to address a growing risk. East Mediter Health J. 2017;23(3):236-44. doi:10.26719/2017.23.3.236

10. Al Suwaidi J, Ali WM, Aleryani SL. Cardiovascular complications of Khat. Clin Chim Acta. 2013;419(0):11-4. doi:10.1016/j. cca.2013.01.007

11. Ali WM, Al Habib KF, Al-Motarreb A, Singh R, Hersi A, Al Faleh H, et al. Acute coronary syndrome and khat herbal amphetamine use: an observational report. Circulation. 2011;124(24):2681-9. doi:10.1161/CIRCULATIONAHA.111.039768

12. Mega TA, Dabe NE. Khat (Catha Edulis) as a risk factor for cardiovascular disorders: systematic review and meta-analysis. Open Cardiovasc Med J. 2017;11:146-55. doi:10.2174/1874192401711010146

13. Hassan MA, Mohamed K, Zipporah N, Hudson L. Khat (Catha edulis) use is associated with the development of gastritis among adults in Nairobi County, Kenya. East African Med J. 2014;91(6):191-201.

14. Orlien SMS, Sandven I, Berhe NB, Ismael NY, Ahmed TA, Stene区Johansen K, et al. Khat chewing increases the risk for developing chronic liver disease: a hospitalవbased case-control study. Hepatology. 2018;68(1):248-57. doi:10.1002/hep.29809 
15. Mossie A, Kindu D, Negash A. Prevalence and severity of depression and its association with substance use in Jimma Town, southwest Ethiopia. Depress Res Treat. 2016;2016:3460462. doi:10.1155/2016/3460462

16. Widmann M, Apondi B, Musau A, Warsame AH, Isse M, Mutiso V, et al. Comorbid psychopathology and everyday functioning in a brief intervention study to reduce khat use among Somalis living in Kenya: description of baseline multimorbidity, its effects of intervention and its moderation effects on substance use. Soc Psychiatry Psychiatr Epidemiol. 2017;52(11):1425-34. doi:10.1007/s00127-017-1368-y

17. Ongeri L, Kirui F, Muniu E, Manduku V, Kirumbi L, Atwoli L, et al. Khat use and psychotic symptoms in a rural Khat growing population in Kenya: a household survey. BMC Psychiatry. 2019;19(1):137. doi:10.1186/s12888-019-2118-3

18. Nakajima M, Dokam A, Khalil NS, Alsoofi M, al'Absi M. Correlates of concurrent khat and tobacco use in Yemen. Subst Use Misuse. 2016;51(12):1535-41. doi:10.1080/10826084.2016.1188950

19. Duresso SW, Matthews AJ, Ferguson SG, Bruno R. Is khat use disorder a valid diagnostic entity? Addiction. 2016;111(9):1666-76. doi:10.1111/add.13421

20. Nakajima M, Hoffman R, Al'Absi M. Level of khat dependence, use patterns, and psychosocial correlates in Yemen: a cross-sectional investigation. East Mediterr Health J. 2017;23(3):161. doi:10.26719/2017.23.3.161

21. Duresso SW, Bruno R, Matthews AJ, Ferguson SG. Khat withdrawal symptoms among chronic khat users following a quit attempt: an ecological momentary assessment study. Psychol Addic Behav. 2018;32(3):320. doi:10.1037/adboooo368

22. Diagnostic and statistical manual of mental disorders, 5th ed. Arlington: American Psychiatric Association; 2013.

23. Mihretu A, Teferra S, Fekadu A. What constitutes problematic khat use? An exploratory mixed methods study in Ethiopia. Subst Abuse Treat Prev Policy. 2017 Mar 21;12(1):17. doi:10.1186/s13011-017-0100-y

24. Patel S. Attitudes to khat use within the Somali community in England. Drugs: Educat, Prevent Policy. 2008;15(1):37-53. doi:10.1080/09687630601138691

25. Sykes W, Coleman N, Desai P, Groom C, Gure M, Howarth R. Perceptions of the social harms associated with khat use. London: Home Office; 2010.

26. Douglas H, Boyle M, Lintzeris N. The health impacts of khat: a qualitative study among Somali-Australians. Med J Aust. 2011;195(11):666-9. doi:10.5694/mja11.10166

27. Zeleke A, Awoke W, Gebeyehu E, Ambaw F. Khat chewing practice and its perceived health effects among communities of Dera Woreda, Amhara region, Ethiopia. Open J Epidemiol. 2013;3:160. doi:10.4236/ojepi.2013.34024

28. Feigin A, Higgs P, Hellard M, Dietze P. The impact of khat use on East African communities in Melbourne: a preliminary investigation. Drug Alcohol Rev. 2011;31(3):288-93.

29. Wedegaertner F, al-Warith H, Hillemacher T, te Wildt B, Schneider U, Bleich S, et al. Motives for khat use and abstinence in Yemen-a gender perspective. BMC Public Health. 2010;10(1):735. doi:10.1186/1471-2458-10-735

30. Heinz AJ, Giedgowd GE, Crane NA, Veilleux JC, Conrad M, Braun AR, et al. A comprehensive examination of hookah smoking in college students: use patterns and contexts, social norms and attitudes, harm perception, psychological correlates and co-occurring substance use. Addict Behav. 2013;38(11):2751-60. doi:10.1016/j.addbeh.2013.07.009

31. Villanti AC, Cobb CO, Cohn AM, Williams VF, Rath JM. Correlates of hookah use and predictors of hookah trial in US young adults. Am J Prevent Med. 2015;48(6):742-6. doi:10.1016/j.amepre.2015.01.010

32. Lopez-Quintero C, Neumark Y. Effects of risk perception of marijuana use on marijuana use and intentions to use among adolescents in Bogotá, Colombia. Drug Alcohol Depend. 2010;109(1):65-72. doi:10.1016/j.drugalcdep.2009.12.011

33. Williams RJ, Herzog TA, Simmons VN. Risk perception and motivation to quit smoking: a partial test of the Health Action Process Approach. Addict Behav. 2011;36(7):789-91. doi:10.1016/j.addbeh.2011.03.003

34. Stimson GV, Fitch C, Rhodes T, Ball A. Rapid assessment and response: methods for developing public health responses to drug problems. Drug Alcohol Rev. 1999;18(3):317-25. doi:10.1080/09595239996464

35. Vincent N, Allsop S, Shoobridge J. The use of Rapid Assessment Methodology (RAM) for investigating illicit drug use: a South Australian experience. Drug Alcohol Rev. 2000;19:419-26. doi:10.1080/713659426

36. National drug strategy household survey 2016: detailed findings. Canberra: Australian Institute of Health and Welfare; 2017.

37. Zou G. A modified Poisson regression approach to prospective studies with binary data. Am J Epidemiol. 2004;159(7):702-6. doi:10.1093/aje/kwhogo

38. McNutt L-A, Wu C, Xue X, Hafner JP. Estimating the relative risk in cohort studies and clinical trials of common outcomes. Am J Epidemiol. 2003;157(10):940-3. doi:10.1093/aje/kwg074

39. Lee J. Odds ratio or relative risk for cross-sectional data? Int J Epidemiol. 1994;23(1):201-3. doi:10.1093/ije/23.1.20

40. Luchenski S, Maguire N, Aldridge RW, Hayward A, Story A, Perri P, et al. What works in inclusion health: overview of effective interventions for marginalised and excluded populations. Lancet. 2018;391(10117):266-80. doi:10.1016/So140-6736(17)31959-1

41. Schmidt@Westhausen AM, Al Sanabani J, Al\Sharabi AK. Prevalence of oral white lesions due to qat chewing among women in Yemen. Oral Dis. 2014;20(7):675-81. doi:10.1111/odi.12188. Epub 2013 Oct 24

42. Abebe W. Khat and synthetic cathinones: emerging drugs of abuse with dental implications. Oral Surg Oral Med Oral Pathol Oral Radiol. 2018;125(2):140-6. doi:10.1016/j.0000.2017.11.015 
43. Nigussie T, Gobena T, Mossie A. Association between khat chewing and gastrointestinal disorders: a cross sectional study. Ethiop J Health Sci. 2013;23(2):123-30. PMID:23950628

44. Abdelkerim AA, Grace M. Challenges to employment in newly emerging African communities in Australia: a review of the literature. Austral Social Work. 2012;65(1):104-19. doi:10.1080/0312407X.2011.616958

45. Orlien SMS, Berhe NB, Morgan MY, Johannessen A. Khat-related liver disease in sub-Saharan Africa: neglected, yet important. Lancet Glob Health. 2019;7(3):e310. doi:10.1016/S2214-109X(18)30527-8

46. Haile D, Lakew Y. Khat chewing practice and associated factors among adults in Ethiopia: further analysis using the 2011 demographic and health survey. PloS one. 2015;10(6):e0130460. doi:10.1371/journal.pone.0130460 